\title{
Allergens and molecular diagnostics of shellfish allergy
}

\section{Part 22 of the Series Molecular Allergology}

\author{
Andreas L. Lopata ${ }^{1,2,3,4}$, Jörg Kleine-Tebbe 5 , Sandip D. Kamath'1, 2,3 \\ 'Australian Institute of Tropical Health and Medicine, James Cook University, Townsville, Queensland, Australia, \\ ${ }^{2}$ Centre for Biodiscovery and Molecular Development of Therapeutics, James Cook University, Townsville, \\ Queensland, Australia, ${ }^{3}$ College of Public Health, Medical and Veterinary Sciences, James Cook University, \\ Townsville, Queensland, Australia, ${ }^{4}$ Centre for Food and Allergy Research, Murdoch Childrens Research Institute, \\ Melbourne, Australia, ${ }^{5}$ Allergy and Asthma Center Westend, Outpatient Clinic Hanf, Ackermann and Kleine-Tebbe, \\ Berlin, Germany
}

Key words prawn allergy shellfish - tropomyosin - crustacean - mollusk arginine kinase

Submitted June 29, 2016

\section{Accepted}

September 7, 2016

Online version http://link.springer. com/journal/40629

Literaturreferat dieser Arbeit auf Deutsch: Seite 14

\section{Abstract}

Shellfish belongs to "The Big 8" food groups causing allergy, which often does not outgrow during childhood. Shellfish is one of the main food allergens in adults and constitutes a diverse group of species subdivided into crustaceans and mollusks, which seem to include similar but also different allergens. Several pan-allergens are characterized in detail, including tropomyosin and arginine kinase, responsible for clinical cross-reactivity with other invertebrate allergen sources, embracing mites, insects, and parasites. Currently, at least seven different shellfish allergens have been identified, mostly from crustaceans. However, only three recombinant allergens are available for IgE-based routine diag-

\section{Background}

In recent years, there has been a steady growth in the production and consumption of seafood and specifically to shellfish. The high higher rate of consumption has led to an increase in adverse health problems among consumers, including allergic reactions. The pattern of allergic symptoms after ingestion of crustaceans appears similar to the symptoms experienced due to other foods. Reactions are immediate, and reported mostly within two hours; however, late phase reactions have been reported up to eight hours after ingestion, particularly to snow crab, cuttlefish, limpet, and abalone [1,2]. Patients may have a single symptom, but often there is a multi-organ involvement. Importantly, respiratory reactions are often seen after ingestion of allergenic seafood and frequently anaphylactic reactions [3]. In partic- nostic, including tropomyosin, arginine kinase, and sarcoplasmic $\mathrm{Ca}^{2+}$-binding protein. Other allergens include myosin light chain, troponin C, triosephosphate isomerase, and actin. This review summarizes the current advances on the molecular characterization of shellfish allergens, clinical cross-reactivity, and current diagnostic approaches for the management of this life-threatening disease.

Cite this as Lopata AL, Kleine-Tebbe J, Kamath SD. Allergens and Molecular Diagnostics of Shellfish Allergy. Allergo J Int 2016;25:210-8

DOI: 10.1007/s40629-016-0124-2

$\begin{array}{ll}\text { Abbrevations } \\ \text { AK } & \text { Arginine kinase } \\ \text { CRD } & \begin{array}{l}\text { Component-resolved diagnosis } \\ \text { DBPCFC }\end{array} \\ & \begin{array}{l}\text { Double blind placebo controlled food } \\ \text { challenge }\end{array} \\ \text { IUIS } & \begin{array}{l}\text { International Union of Immunological } \\ \text { Societies }\end{array} \\ \text { MLC } & \text { Myosin light chain } \\ \text { OAS } & \text { Oral allergy syndrome } \\ \text { SCBP } & \text { Sarcoplasmic calcium binding protein } \\ \text { TIM } & \text { Triosephosphate isomerase } \\ \text { TM } & \text { Tropomyosin } \\ \text { TnC } & \text { Troponin C }\end{array}$


ular, the oral allergy syndrome (OAS) seems to be very often experienced by crustacean allergic subjects. Shrimp has also been implicated in food-dependent exercise-induced anaphylaxis [4].

Currently, $2 \%$ of the general world population is af fected by shellfish allergy, with much higher rates in countries with high seafood consumption. Unlike many other food allergies, most shellfish allergy persists for life in the affected individual.

\section{Classification of shellfish groups}

Patients with allergy to shellfish may fail to identify the offending seafood species, often as a result of confusion regarding the different common names used to describe diverse seafood. The two invertebrate phyla of arthropods and mollusks are generally referred to as "shellfish" (Fig. 1).

Crustaceans are, perhaps surprisingly, classified as arthropods together with spiders and insects. This might provide an explanation for the observed molecular and clinical cross-reactivity discussed in detail below.

The group of mollusks is a large and diverse group, subdivided into the classes bivalve, gastropod, and cephalopod, including several important seafood groups including mussels, oysters, abalone, snails, and squid (calamari).

\section{Prevalence of shellfish allergy}

The prevalence of allergic reactions to seafood is usually higher when the consumption plays a greater part in the diet of the observed community. It is generally considered that crustaceans and mollusks are among the foods that most commonly provoke severe anaphylaxis [6]. A recent study established surprisingly that seafood allergies are a significant health concern affecting approximately 6.5 million people in the United States (US) - more than twice as common as peanut allergy. The telephone survey among 14,948 individuals reported 5.9\% with shellfish allergy, and seafood allergy was almost 5 -times more common among adults compared to children [7].

In France, in a study by Andre and co-workers among 580 patients with adverse reactions to food, $34 \%$ were identified having specific IgE to crab [8]. A study from South Africa including 105 individuals with perceived adverse reactions to seafood confirmed sensitization to shrimps and rock lobster in almost $50 \%[1,9]$.

While seafood allergy is common in Western countries such as Europe, the US, and Australia, it seems that in Asian countries allergic reactions to shellfish are of greater importance among adults and children $[10,11,12]$. This clearly supports the

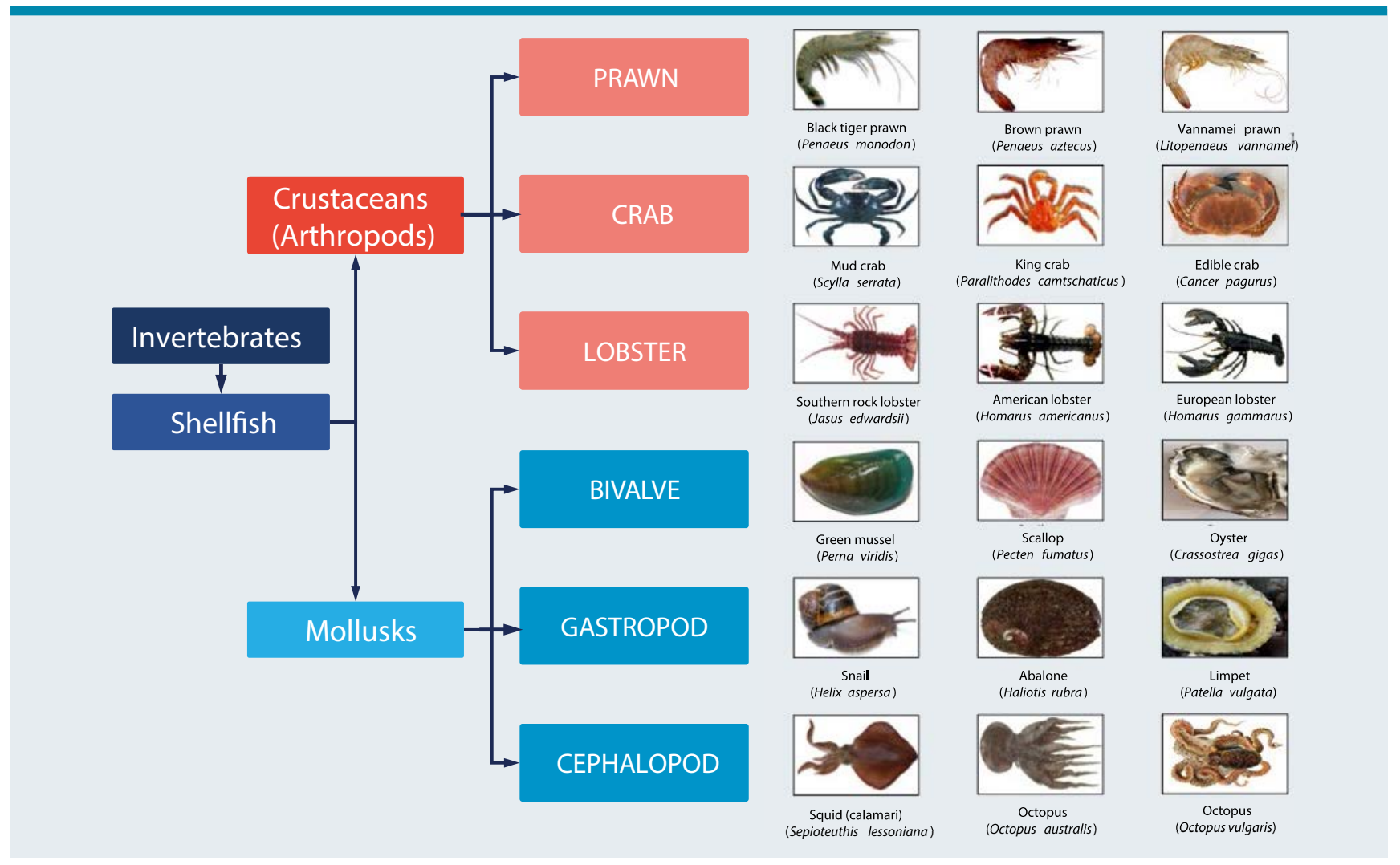

Fig. 1: Schematic classification of most commonly consumed shellfish species. 


\begin{tabular}{|c|c|c|c|c|c|}
\hline Biochemical name & Molecular weight & $\begin{array}{l}\text { Heat stability and } \\
\text { IgE binding }\end{array}$ & Route of exposure & $\begin{array}{l}\text { IgE sensitization }(\%) \\
\text { ( } \mathrm{n}=\text { subjects tested) }\end{array}$ & Physiological function \\
\hline Tropomyosin & $34-38 \mathrm{kDa}$ & $\begin{array}{l}\text { highly heat stable } \\
\text { and lgE reactive }\end{array}$ & $\begin{array}{l}\text { ingestion } \\
\text { inhalation }\end{array}$ & $\begin{array}{l}\text { Pen a } 1,51 \%(n=45)[19] \\
\text { Lit v } 1,61 \%(n=19)[46] \\
\text { Pen } m 1,62 \%(n=16)[22]\end{array}$ & $\begin{array}{l}\text { Coiled-coil protein that binds to } \\
\text { actin and regulates interaction of } \\
\text { troponin and myosin }\end{array}$ \\
\hline Arginine kinase & $40-45 \mathrm{kDa}$ & $\begin{array}{l}\text { labile, but can elicit } \\
\text { lgE binding }\end{array}$ & $\begin{array}{l}\text { ingestion } \\
\text { inhalation }\end{array}$ & $\begin{array}{l}\text { Pen } m 2,50 \%(n=16)[22] \\
\text { Lit v 2, } 21 \%(n=19)[46]\end{array}$ & $\begin{array}{l}\text { A kinase that catalyzes reversible } \\
\text { transfer of phosphoryl group from } \\
\text { ATP to arginine }\end{array}$ \\
\hline Myosin light chain & $17-20 \mathrm{kDa}$ & stable & ingestion & $\begin{array}{l}\text { Pen } m 3,31 \%(n=16)[22] \\
\text { Lit v 3, 31\% }(n=19)[46]\end{array}$ & $\begin{array}{l}\text { Regulatory function in smooth } \\
\text { muscle contraction when phos- } \\
\text { phorylated by MLC kinase }\end{array}$ \\
\hline $\begin{array}{l}\text { Sarcoplasmic } \\
\text { calcium binding } \\
\text { protein }\end{array}$ & $20-25 \mathrm{kDa}$ & stable & ingestion & $\begin{array}{l}\text { Pen } m 4,19 \%(n=16)[22] \\
\text { Lit v 4, } 21 \%(n=19)[46]\end{array}$ & $\begin{array}{l}\text { Binds to cytosolic calcium }\left(\mathrm{Ca}^{2+}\right) \\
\text { and acts as a calcium buffer regu- } \\
\text { lating calcium based signalling }\end{array}$ \\
\hline Troponin C & $20-21 \mathrm{kDa}$ & unknown & ingestion & Cra c 6, $29 \%(n=31)[29]$ & $\begin{array}{l}\text { Regulates interaction of actin and } \\
\text { myosin during muscle contraction } \\
\text { on binding to calcium }\end{array}$ \\
\hline $\begin{array}{l}\text { Triosephosphate } \\
\text { isomerase }\end{array}$ & $28 \mathrm{kDa}$ & labile & $\begin{array}{l}\text { ingestion } \\
\text { inhalation }\end{array}$ & $\begin{array}{l}\text { Pen } m 8,19 \%(n=16)[22] \\
\text { Cra c 8, 23\% }(n=31)[29]\end{array}$ & $\begin{array}{l}\text { Key enzyme in glycolysis; catalyses } \\
\text { conversion of dihydroxyacetone } \\
\text { phosphate to glyceraldehyde } \\
\text { 3-phosphate }\end{array}$ \\
\hline
\end{tabular}

view that the likelihood of becoming sensitized to shellfish seems to correlate with geographical eating habits and is most likely underreported in many Asian populations.

Not only ingestion of shellfish can cause sensitization, but also exposure during processing in factories and domestic environment. There seems to be a strong correlation between high concentration of air-borne allergens and increased allergic sensitization $[13,14,15,16]$.

\section{Structure and biological functions of shellfish allergens}

Over the past 20 years, several shellfish allergens, particularly in crustaceans have been identified and sequenced. Currently, 34 allergens have been identified and characterized in detail from various crustacean and mollusk species and registered in the International Union of Immunological Societies (IUIS) Allergen Database (Tab. 1) (www. allergen.org) [17]. The biochemical characteristics of shellfish allergenic proteins are typically of low molecular weight, high water solubility, high heat stability, and an acidic isoelectric point. Almost all of the known characterized allergens are found in the edible portions of various shellfish species. However, some protease-based allergens, (non-IgE-mediated), are present in the gastrointestinal regions of the different shellfish species [18]. The allergen family specific properties of shellfish allergens are described below and summarized in Tab. 1 and Tab. 2.

\section{Tropomyosin Pen $\mathrm{m} 1$}

Tropomyosin (TM) is the major allergenic protein across all edible crustacean and mollusk species. More than $60 \%$ of shellfish allergic patients are sensitized and react to TM, often leading to severe systemic reactions. Tropomyosin-specific IgE is frequently used to predict clinical outcomes of shrimp allergy with a positive predictive value of $0.72[19$, 20].

This allergen is an alpha-helical coiled-coil dimeric protein that binds along the length of actin and regulates the cooperation of troponin and myosin, thus controlling the contraction of muscle fibers [21]. The primary structure is highly conserved across various invertebrate species. This seems to be the main reason for high IgE-mediated allergenic cross-reactivity across various shellfish species as described below in detail. Interestingly, even though crustacean and mollusk TMs are allergenic, they share only very low amino acid sequence identities of 55 to $70 \%$.

Allergenic TMs have generally molecular weights of between 33 and $38 \mathrm{kDa}$ and are highly stable to heat-treatment, capable of retaining allergenicity even after cooking and high-pressure processing. According to the Allfam database (www.meduniwien.ac.at/allfam), the TM family is the largest 


\section{Tab. 2: Characterized allergens in crustacean and mollusk species*}

\begin{tabular}{|c|c|c|c|c|c|c|c|c|c|}
\hline & & Shellfish species & Common names & 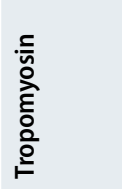 & 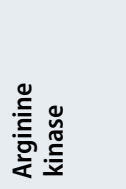 & 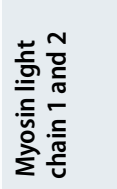 & 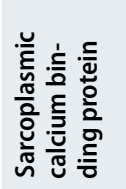 & 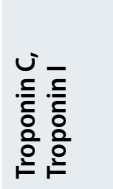 & 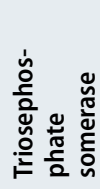 \\
\hline \multirow[t]{14}{*}{ Crustaceans } & \multirow[t]{9}{*}{ Prawn } & Penaeus monodon & $\begin{array}{l}\text { black tiger prawn, giant tiger } \\
\text { prawn, Asian tiger shrimp }\end{array}$ & Pen $\mathrm{m} 1^{\mathrm{b}}$ & Pen $\mathrm{m} 2^{\mathrm{b}}$ & Pen $\mathrm{m} 3$ & Pen $\mathrm{m} 4{ }^{\mathrm{b}}$ & Pen $\mathrm{m} 6$ & Crac 8 \\
\hline & & Penaeus aztecus & brown shrimp & Pen a $1^{a}$ & - & - & - & - & - \\
\hline & & Crangon crangon & $\begin{array}{l}\text { North sea shrimp, common } \\
\text { shrimp }\end{array}$ & Crac 1 & Crac 2 & Crac 5 & Crac 4 & Crac 6 & - \\
\hline & & $\begin{array}{l}\text { Litopenaeus } \\
\text { vannamei }\end{array}$ & $\begin{array}{l}\text { Pacific white shrimp, vannamei } \\
\text { shrimp }\end{array}$ & Lit v 1 & Lit $\vee 2$ & Lit v 3 & Lit v 4 & - & - \\
\hline & & $\begin{array}{l}\text { Melicertus } \\
\text { latisulcatus }\end{array}$ & $\begin{array}{l}\text { King prawns, Western king } \\
\text { prawns }\end{array}$ & Mell 1 & - & - & - & -- & - \\
\hline & & Pandalus borealis & Northern shrimp, Pink shrimp & Pan b 1 & - & - & - & - & - \\
\hline & & Penaeus indicus & Indian white prawn & Pen i 1 & - & - & - & - & - \\
\hline & & Metapenaeus ensis & Greasyback shrimp, Sand shrimp & Met e 1 & - & - & - & - & - \\
\hline & & $\begin{array}{l}\text { Archaeopotamobi- } \\
\text { us sibiriensis }\end{array}$ & ND & - & - & - & - & - & $\operatorname{Arcs} 8$ \\
\hline & \multirow[t]{2}{*}{ Crab } & Charybdis feriatus & Crucifix crab & Cha f 1 & - & - & - & - & - \\
\hline & & Portunus pelagicus & Blue swimmer crab & Por $p 1$ & - & - & - & - & - \\
\hline & \multirow[t]{3}{*}{ Lobster } & $\begin{array}{l}\text { Homarus } \\
\text { americanus }\end{array}$ & American lobster & Hom a 1 & & Hom a 3 & & Hom a 6 & \\
\hline & & $\begin{array}{l}\text { Panulirus } \\
\text { stimpsonii }\end{array}$ & Spiny lobster & Pan s 1 & - & - & - & - & - \\
\hline & & $\begin{array}{l}\text { Pontastacus } \\
\text { leptodactylus }\end{array}$ & Narrow-clawed crayfish & Pon i 1 & - & - & - & - & - \\
\hline \multirow[t]{4}{*}{ Mollusks } & Bivalve & ND & & - & - & - & - & - & - \\
\hline & \multirow[t]{2}{*}{ Gastropod } & Helix aspersa & Garden snail & Hel as 1 & - & - & - & - & - \\
\hline & & Haliotis midae & South African abalone & Hal m 1 & - & - & - & - & - \\
\hline & Cephalopod & Todarodes pacificus & Pacific squid & Tod p 1 & - & - & - & - & - \\
\hline
\end{tabular}

"food" allergen family in animal sources, consisting of currently 47 identified TMs, mostly from crustacean species [17].

\section{Arginine kinase Pen $\mathrm{m} 2$}

Arginine kinase (AK) has been identified in over six crustacean and one mollusk species.

IgE sensitization to the $40-42 \mathrm{kDa} \mathrm{AK}$ has been demonstrated in $21-50 \%$ of adults and $67 \%$ children [22, 23]. Although heat labile, IgE binding has been demonstrated to $\mathrm{AK}$ in heat-treated shrimps, which may be due to remaining intact IgE epitopes on aggregated AK $[22,24]$. Interestingly, crustacean AK along with TM has also been implicated in inhalational exposure and sensitization among crab processing workers [25]. Crustacean AK has been demonstrated to cross-react to ingested insect $\mathrm{AK}$ as well as being implicated in seafood-mite cross-reactivity [26, 27].

\section{Myosin light chain Pen $\mathbf{m} 3$}

The EF hand domain superfamily is the second largest group of all allergens, after profilins, which encompasses both food and inhalant allergens from animal and plant sources. Three classes of shellfish allergens are EF hand domain proteins, which include myosin light chain (MLC), sarcoplasmic calcium binding proteins, and troponin.

MLC is mainly found in smooth muscles in complex with myosin heavy chain motor domains. Myo- 
sin light chains have a molecular weight between 17 and $20 \mathrm{kDa}$, are well characterized in four crustacean species and seem to be heat stable. Currently, there is a lack of data on immunological cross-reactivity of MLC among crustaceans, mollusks, or other invertebrate species.

\section{Sarcoplasmic calcium binding protein Pen $\mathrm{m} \mathbf{4}$}

Sarcoplasmic calcium binding proteins (SCBPs) are also members of the EF hand calcium binding protein family incorporating the helix-loop-helix motif in the primary amino acid sequence. It has a molecular weight of approximately $20 \mathrm{kDa}$ and an isoelectric point of 5, and can elicit IgE binding even after heat treatment [22]. Recent studies have highlighted the relevance of SCBP as a shellfish allergen. Ayuso et al. demonstrated IgE recognition in $85 \%$ of shrimp allergic children, which is much higher compared to tropomyosin [28]. More importantly, it has been shown that specific IgE to SCBP, in addition to that of TM, is associated with clinical reactivity to shrimps [20].

\section{Troponin C Cra c 6}

Troponin C ( TnC) has been characterized in shrimps, but also as important cockroach allergen
(Bla g 6 and Per a 6). Similar to SCBP and MLC, TnC is an EF hand calcium binding protein. Troponin $\mathrm{C}$ is approximately $20 \mathrm{kDa}$ in size and its possible heat stability is not fully understood. The IgE binding frequency to $\mathrm{TnC}$ is with $15 \%$ lower as reactivity to TM, AK, or SCBP.

\section{Triosephosphate isomerase Cra c 8}

Triosephosphate isomerase (TIM) has been characterized in shrimps (Cra c 8), crayfish (Arc s 8), and cockroach (Bla g TPI). It has an approximate molecular weight of $28 \mathrm{kDa}$ and is probably heat sensitive [29]. The clinical and immunological cross-reactivity of TIM among various invertebrate species are not well understood and amino acid sequences have not been performed.

\section{Clinical and immunological cross-reactivity}

True sensitization to shellfish specific allergens can be hampered due the highly cross-reactive nature of some allergenic proteins. The most well known pan-allergen is tropomyosin, being the major cause for reported clinical cross-reactivity among and between crustaceans and mollusks, but also other invertebrates, including mites, cockroaches, and parasites (Fig. 2). It is known that tropomyosin has

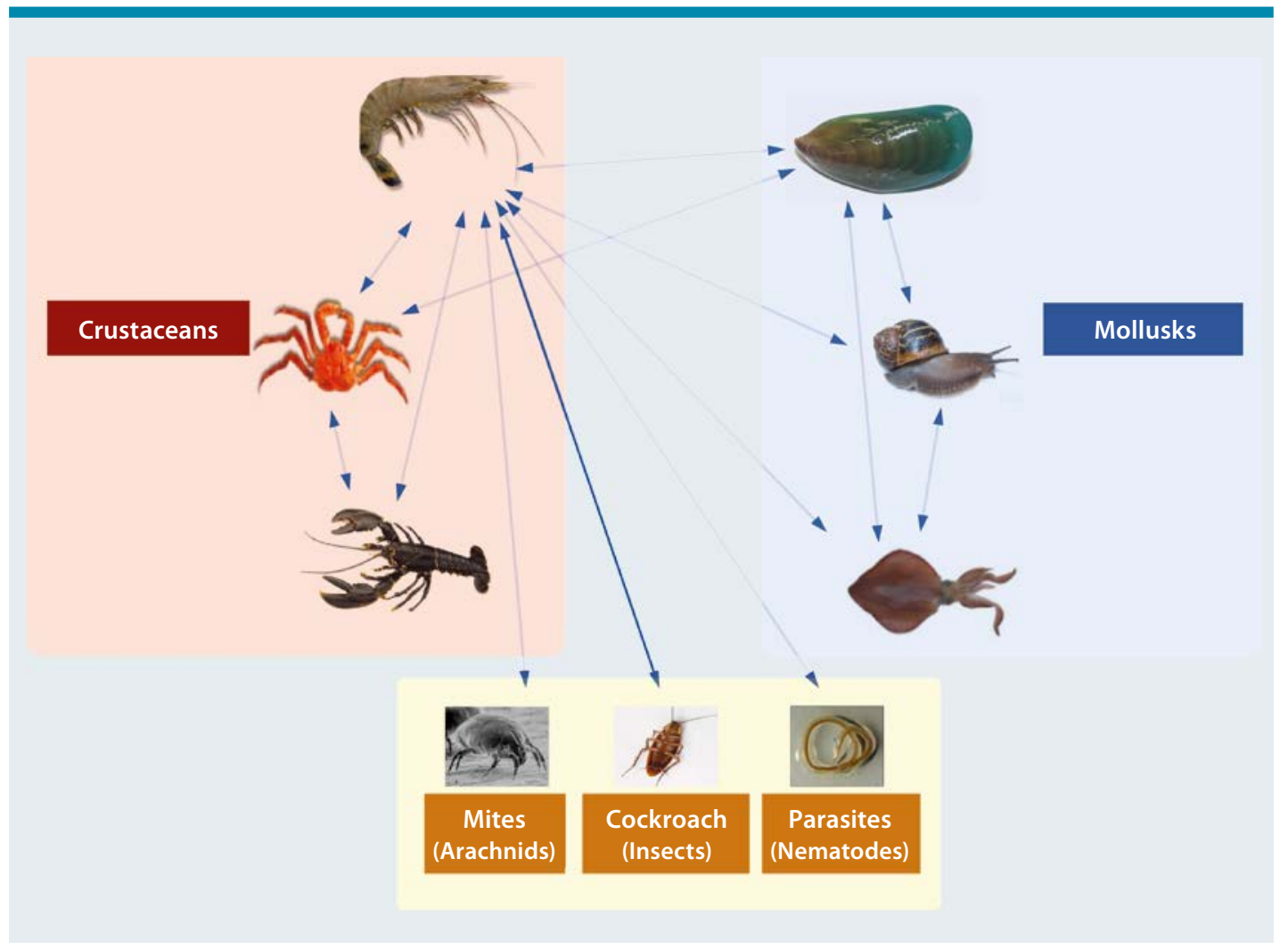

Fig. 2: Graphical representation of immunological cross-reactivity among crustacean and mollusk sp cies as well as to mites, insects, and nematodes. 
mainly linear IgE epitopes and is of great importance in determining the degree of cross-reactivity between different shellfish species. Tropomyosin is highly conserved among various crustacean species such as prawn, crabs, and lobsters with amino acid identities reaching 95-100\%. Therefore, IgE crossreactivity is very frequent among crustacean species $[30,31,32,33,34]$.

Within the mollusk group, hypersensitivity cross-reaction is often seen in allergic individuals, as determined for ten different species of cephalopods [35]. Similar results were shown for four species of gastropods (disc abalone, turban shell, whelk, and Middendorf's buccinum) and seven species of bivalves (bloody cockle, Japanese oyster, Japanese cockle, surf clam, horse clam, razor clam, and short neck clam) [36].

Increasingly important seems to be IgE cross-sensitization between tropomyosin from shellfish and other important allergenic invertebrates, including dust-mites and cockroaches (Fig. 2). It was demonstrated that IgE against mite tropomyosin (Der $\mathrm{p}$ 10) reacted very strongly to shrimp tropomyosin, although tropomyosin is present in very low concentrations in house dust mites [37]. More interestingly, reactivity to shrimp has been demonstrated in subjects with house dust-mite allergy, who have never been exposed to shrimps due to religious eating habits [38].

\section{Potential advantages of component- resolved diagnosis in shellfish allergy}

Applying single allergenic molecules from shellfish for allergen-specific IgE detection could potentially modify

1. test sensitivity (improving the limit of quantitation to shellfish allergens of rare abundance or low stability) and/or modify

2. analytical specificity, particularly if specific $\operatorname{IgE}$ is detectable to

a) risk associated molecules (being more likely responsible for severe reactions and/or more specific for children or adults),

b) indicators of cross-reactivity (involved in broad serological cross-reactions between different shellfish species),

c) markers of primary species- and/or familyspecific sensitizations (facilitating the identification of unique allergic sensitizations to certain shellfish species or families).

The listed advantages of component-resolved diagnosis (CRD) require some allergen-related knowledge about

_ abundance of single allergens in the shellfish body (and resulting extracts),

- location of the allergen in the organism (edible or non-edible parts),
— water solubility (for proper extraction),

- stability and behavior to thermal and gastric degradation,

_ frequency of sensitization to the single allergen in question,

_ degree of inter-species or inter-family related cross-reactivity,

_risk to elicit severe allergic reactions.

Specific IgE to TM, thanks to its high abundance and stability, is picked up reasonable easily using heated protein extracts from probably most shellfish species. Thus, there is no particular need to further increase test sensitivity. However, increased analytical specificity of TM in molecular-based serological tests will help to identify patients at risk for severe allergic reactions and, in addition, indicate broad cross-reactivity to TM from other shellfish species and perhaps insects and mites. Testing IgE to more than one TM is probably providing more information about cross-reactivity between crustaceans and mollusks.

Similar assumptions are related to the other described shellfish allergens (see above), i.e., AK, MLC, SCBP, TnC, TIM: being part of the edible part of shellfish, with basic functions in muscle fibers or general energy metabolism, they are presumably also highly conserved, showing variable degrees of cross-reactivity, which has not been studied yet. Increasing test sensitivity through the use of single molecules might be useful in less stable allergens (i. e., AK, TIM), but not necessarily for more robust proteins (i. e., MLC, SCBP). Increased analytical specificity can assist uncovering associated risks, i. e., in case of IgE to SCBP [20]. However, none of these candidates might serve as a single marker for species-specific sensitization due to variable degrees of IgE-related cross-reactivity, which still needs to be addressed. Recent advances in PCR based allergen-specific IgE quantification have further improved the sensitivity and specificity to single allergens, using serum from a finger-prick, which is of particular advantage for infant allergy testing [39].

In conclusion, no species-specific allergens have been identified so far, making it difficult to precisely diagnose allergy to a specific crustacean or mollusk species with the use of allergen molecules [3, 40]. If more of the already identified and additional allergens are available for diagnostics, it might be helpful to test one per protein family, ensuring maximum test sensitivity and enhanced molecular specificity, particularly if TM is not the major allergen. This does, however, not solve the question of potential clinical cross-reactions to closely related shellfish species: only anamnestic data or oral challenges can indicate or rule out clinically relevant allergic reactions to certain shellfish species. 


\section{Diagnostics separating IgE-mediated allergy from other reactions}

Serum based IgE quantification tests are available for a wide variety of crustacean and mollusk species as well as for cross-reactive invertebrate species such as dust-mites and cockroaches. IgE quantification tests for single component allergens are currently only available for shrimp tropomyosin (rPen a 1). However, some additional shellfish allergens are available in multiplex (microarray) format for prawn tropomyosin (nPen $\mathrm{m} 1$ ), arginine kinase (nPen $\mathrm{m}$ 2), and sarcoplasmic calcium binding protein (rPen $\mathrm{m} 4$ ).

Approximately $60 \%$ of patients with clinical allergy to crustacean demonstrate specific IgE binding to tropomyosin. It has been suggested that IgE reactivity to tropomyosin is a better predictor of shrimp allergy as compared to skin prick testing (SPT) or IgE to whole shrimp extract $[19,23]$. However, also sarcoplasmic calcium-binding protein (Pen $\mathrm{m}$ 4) reactivity has been associated with clinical reactivity to shrimp. The combination of reactivity to both allergens might increase the sensitivity to detect clinically allergic patients, but has still to be confirmed.

The consumption of seafood is very different from most other food allergen sources. It can trigger clinical adverse symptoms, although non-allergic in origin, being similar in clinical presentation to true IgE-mediated allergic reactions. These substances are found in seafood much more frequently as compared to any other food source. An atypical clinical history or an inconsistent history always suggests a non-atopic etiology, such as contamination with marine bio-toxins, parasites, bacteria, and viruses $[41,42]$. Because of the similarity in clinical reactions of affected individuals, it is essential to differentiate adverse reactions from true shellfish allergy and understand the molecular nature of the offending allergens for improved component-resolved diagnosis.

Food challenge or double blind placebo controlled food challenge (DBPCFC) can be performed to confirm clinical reactivity to crustacean and mollusk species. However, such provocation tests are not performed routinely because of increased risk and costs, and are only performed for investigating individual cases.

\section{Outlook for future diagnostic options}

Most of the clinical studies on cross-reactivity have been conducted using tropomyosin as the major pan-allergen. However, other shellfish allergens may play a role in immunological cross-sensitization. A recent study has shown that allergens other than tropomyosin, such as arginine kinase, might also be responsible for cross-reactivity between shellfish and inhalant invertebrate allergen sources $[27,43]$. In addition, hemocyanin has been demonstrated to be cross-reactive and is also a known cockroach allergen $[44,45]$.

However, an in-depth investigation into the conservation or relevance of specific IgE epitopes between pan-allergens from crustaceans and mollusks and clinical cross-reactivity to mites and cockroaches has not been conducted or confirmed using a larger number of shellfish allergic patients.

\section{Suggestions for present clinical practice}

Diagnosis of shellfish allergy is based on

_clinical history,

— sensitization tests (allergen-specific IgE tests; skin tests), and

_oral challenge test, if needed.

In case of severe allergic reaction, allergen-specific IgE should precede any in vivo tests, i.e., SPT, to avoid any risks for the shellfish allergic patient. IgE diagnostics should include

- total IgE (for improved interpretation of the quantitative allergen-specific IgE values),

-allergen-specific IgE preferably to the reactioneliciting (or biologically closely related) shellfish species,

_allergen-specific IgE to Pen a 1, the currently only available TM for singleplex testing from brown shrimp (Penaeus aztecus).

A step-by-step guide could be as follows:

a) If extract- and TM-specific IgE results are positive with quantitative IgE-levels being higher to TM than to the whole extract, immunodominant sensitization to shellfish TM is likely, and broad (serological) cross-reactivity to other shellfish species is to be expected. During interpretation of the test, concordance between recorded symptoms and the identified shellfish species should be checked. Only in case of corresponding symptoms and a positive sensitization test, clinically relevant allergy has successfully been demonstrated.

b) If only the extract-specific IgE, but not the TM-specific IgE is positive, sensitization to TM is unlikely, but other shellfish allergens might be involved.

c) If both IgE-tests (shellfish extract- and TM-specific IgE) turn out to be negative, it is mandatory to perform a skin test, i.e., SPT with a commercial shellfish extract and/or a (titrated) SPT with native material (i.e., prick-prick-test with fresh shellfish species, if possible raw and cooked).

d) In case of a clearly positive SPT result an immediate-type sensitization is likely, particularly if healthy control individuals do not react to the applied skin test material.

e) In case of clearly negative skin test results, IgE-mediated sensitization to the tested shellfish 
species becomes very unlikely and differential diagnoses other than IgE-mediated allergic reactions to shellfish should be considered.

f) Additional testing with other shellfish species has limited value for subsequent consulting of the patient: in case of positive skin or IgE test results, serological cross-reactivity has been demonstrated, which does not always translate into clinical cross-reactivity. However, in case of a clearly negative skin and/or IgE response to related or biologically more distant shellfish specifies (serological) cross-reactivity and subsequent clinical cross-reactivity becomes unlikely.

g) In case of doubt or mismatch between case history and diagnostic results, carefully titrated oral challenge tests with the suspected shellfish species might solve the discrepancies. However, due to the risk for the patient in case of previous severe allergic reactions and limited specialized centers, they are not frequently performed. A negative provocation test, if previous sensitizations tests turned out negative, is usually safe and an appropriate way to rule out a present food allergy to shellfish.

In general, patients with proven shellfish allergy should avoid a broad range of related shellfish species (crustacean or mollusk), unless they have already tolerated other (presumably biologically more distant) shellfish species. This rather cautious approach takes into account that allergic subjects are not necessarily familiar with huge variety of present shellfish species, their biological relationship and the composition in mixed seafood dishes, particularly from non-self prepared meals.

Due to the often long-lasting nature of IgE-mediated allergies to shellfish species patients with proven allergic reactions should avoid shellfish permanently, unless subsequent controlled challenges have ruled out a still present clinical reactivity.

\section{Prof. Dr. Andreas L. Lopata}

Pharmacy and Medical Research

College of Public Health, Medical and

Veterinary Sciences

James Cook University (Townsville Campus)

Douglas, Queensland 4811

Australia

E-Mail: andreas.lopata@jcu.edu.au

\section{Conflict of interest}

The authors declare that there are no conflicts of interest.

\section{Cite this as}

Lopata AL, Kleine-Tebbe J, Kamath SD. Allergens and Molecular Diagnostics of Shellfish Allergy. Allergo J Int 2016;25:210-8

DOI: $10.1007 / \mathrm{s} 40629-016-0124-2$

\section{References}

1. Lopata AL, Zinn C, Potter PC. Characteristics of hypersensitivity reactions and identification of a unique $49 \mathrm{kd}$ IgE-binding protein (Hal-m-1) in abalone (Haliotis midae). J Allergy Clin Immunol 1997;100:642-8

2. Villacis J, Rice TR, Bucci LR, El-Dahr JM, Wild L, Demerell D, et al. Do shrimp-allergic individuals tolerate shrimp-derived glucosamine? Clin Exp Allergy 2006;36:1457-61

3. Matricardi PM, Kleine-Tebbe J, Hoffmann H J, Valenta R, Hilger C, Hofmaier S, et al. EAACI Molecular Allergology User's Guide. Pediatr Allergy Immunol 2016;27(Suppl.23):1-236

4. Zhang $\mathrm{Y}$, Matsuo $\mathrm{H}$, Morita E. Cross-reactivity among shrimp, crab and scallops in a patient with a seafood allergy. Journal of Dermatology 2006; 33:174-7

5. Lopata AL, SD K. Allergy to crustacean and mollusks (shellfish). In: Matricardi PM K-TJ, Hoffmann H J, Valenta R, and Ollert M, editor. EAACI Molecular Allergology User's Guide: Published by the European Academy of Allergy and Clinical Immunology; 2016. p. 173-83

6. Tham EH, Tay SY, Lim DLC, Shek LPC, Goh AEN, Giam YC, et al. Epinephrine auto-injector prescriptions as a reflection of the pattern of anaphylaxis in an Asian population. Allergy Asthma Proc 2008;29:211-5

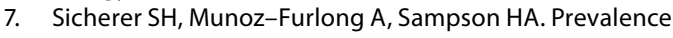
of seafood allergy in the United States determined by a random telephone survey. J Allergy Clin Immunol 2004;114:159-65

8. Andre F, Andre C, Colin L, Cacaraci F, Cavagna S. Role of new allergens and of allergens consumption in the increased incidence of food sensitizations in France. Toxicology 1994;93:77-83

9. Zinn C, Lopata A, Visser M, Potter PC. The spectrum of allergy to South African bony fish (Teleosti). Evaluation by double-blind, placebo-controlled challenge. S Afr Med J 1997;87:146-52

10. Goh DL, Lau YN, Chew FT, Shek LP, Lee BW. Pattern of food-induced anaphylaxis in children of an Asian community. Allergy 1999;54:84-6

11. Shek LPC, Cabrera-Morales EA, Soh SE, Gerez I, Ng PZ, Yi $F C$, et al. A population-based questionnaire survey on the prevalence of peanut, tree nut, and shellfish allergy in 2 Asian populations. Journal of Allergy and Clinical Immunology 2010;126:324-U50

12. Thalayasingam M, Gerez IF, Yap GC, Llanora GV, Chia IP, Chua $\mathrm{L}$, et al. Clinical and immunochemical profiles of food challenge proven or anaphylactic shrimp allergy in tropical Singapore. Clinical and Experimental Allergy 2015;45:687-97

13. Baatjies R, Meijster T, Heederik D, Jeebhay MF. Exposure-response relationships for inhalant wheat allergen exposure and asthma. Occup Environ Med 2015;72:200-7

14. Kamath SD, Thomassen MR, Saptarshi SR, Nguyen HM, Aasmoe L, Bang BE, et al. Molecular and immunological approaches in quantifying the air-borne food allergen tropomyosin in crab processing facilities. International Journal of Hygiene and Environmental Health 2014;217:740-50

15. Bonlokke JH, Gautrin D, Sigsgaard T, Lehrer SB, Maghni K, Cartier A. Snow crab allergy and asthma among Greenlandic workers - a pilot study. International Journal of Circumpolar Health 2012;71

16. Gautrin D, Cartier A, Howse D, Horth-Susin L, Jong M, Swanson M, et al. Occupational asthma and allergy in snow crab processing in Newfoundland and Labrador. Occup Environ Med 2010;67:17-23

17. Radauer C, Bublin M, Wagner S, Mari A, Breiteneder H. Allergens are distributed into few protein families and possess a restricted number of biochemical functions. Journal of Allergy and Clinical Immunology 2008;121:847-52 e7

18. Sun S, Lopata A. The role of shellfish proteases in allergic diseases and inflammation. Current Allergy and Clinical Immunology 2010;23:174-9 
19. Gámez C, Sánchez-García S, Ibáñez MD, López R, Aguado $\mathrm{E}$, López $\mathrm{E}$, et al. Tropomyosin IgE-positive results are a good predictor of shrimp allergy. Allergy 2011;66:1375-83

20. Pascal M, Grishina G, Yang AC, Sanchez-Garcia S, Lin J, Towle D, et al. Molecular Diagnosis of Shrimp Allergy: Efficiency of Several Allergens to Predict Clinical Reactivity. Journal of Allergy and Clinical Immunology - In practice 2015;3:521-9 e10

21. Oguchi Y, Ishizuka J, Hitchcock-DeGregori SE, Ishiwata S, Kawai M. The Role of Tropomyosin Domains in Cooperative Activation of the Actin-Myosin Interaction. Journal of Molecular Biology 2011;414:667-80

22. Kamath SD, Rahman AM, Voskamp A, Komoda T, Rolland $J M, O^{\prime}$ Hehir RE, et al. Effect of heat processing on antibody reactivity to allergen variants and fragments of black tiger prawn: A comprehensive allergenomic approach. Molecular nutrition \& food research 2014:58:1144-55

23. Yang AC, Arruda LK, Santos ABR, Barbosa MCR, Chapman MD, Galvao CES, et al. Measurement of IgE antibodies to shrimp tropomyosin is superior to skin prick testing with commercial extract and measurement of IgE to shrimp for predicting clinically relevant allergic reactions after shrimp ingestion. J Allergy Clin Immunol 2010;125:872-8

24. Shen HW, Cao MJ, Cai QF, Ruan MM, Mao HY, Su WJ, et al. Purification, Cloning, and Immunological Characterization of Arginine Kinase, a Novel Allergen of Octopus fangsiao. Journal of Agricultural and Food Chemistry 2012;60:2190-9

25. Abdel Rahman AM, Kamath SD, Lopata AL, Robinson JJ, Helleur RJ. Biomolecular characterization of allergenic proteins in snow crab (Chionoecetes opilio) and de novo sequencing of the second allergen arginine kinase using tandem mass spectrometry. Journal of Proteomics 2011;74:231-41

26. Srinroch $C$, Srisomsap $C$, Chokchaichamnankit D, Punyarit $P$, Phiriyangkul P. Identification of novel allergen in edible insect, Gryllus bimaculatus and its cross-reactivity with Macrobrachium spp. allergens. Food Chem 2015;184:160-6

27. Gamez C, Zafra MP, Boquete M, Sanz V, Mazzeo C, Ibanez $M D$, et al. New shrimp lgE-binding proteins involved in mite-seafood cross-reactivity. Molecular Nutrition and Food Research 2014;

28. Ayuso R, Grishina G, Ibanez MD, Blanco C, Carrillo T, Bencharitiwong $R$, et al. Sarcoplasmic calcium-binding protein is an EF-hand-type protein identified as a new shrimp allergen. J Allergy Clin Immunol 2009;124:114-20

29. Bauermeister K, Wangorsch A, Garoffo LP, Reuter A, Cont A, Taylor SL, et al. Generation of a comprehensive panel of crustacean allergens from the North Sea Shrimp Crangon crangon. Mol Immunol 2011;48:1983-92

30. Zhang Y, Matsuo H Fau - Morita E, Morita E. Cross-reactivity among shrimp, crab and scallops in a patient with a seafood allergy. Journal of Dermatology 2006;

31. Abramovitch JB, Kamath S, Varese N, Zubrinich C, Lopata $A L, O$ 'Hehir RE, et al. IgE Reactivity of Blue Swimmer Crab

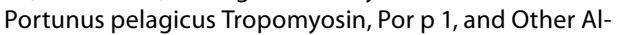
lergens; Cross-Reactivity with Black Tiger Prawn and Effects of Heating. PLoS ONE 2013;8:e67487
32. Nakano S, Yoshinuma T, Yamada T. Reactivity of shrimp allergy-related IgE antibodies to krill tropomyosin. Int Arch Allergy Immunol 2008;145:175-81

33. Motoyama K, Suma Y, Ishizaki S, Nagashima Y, Shiomi K. Molecular cloning of tropomyosins identified as allergens in six species of crustaceans. Journal of Agricultural and Food Chemistry 2007;55:985-91

34. Ayuso R, Reese G, Leong-Kee S, Plante M, Lehrer SB. Molecular basis of arthropod cross-reactivity: IgE-binding cross-reactive epitopes of shrimp, house dust mite and cockroach tropomyosins. Int Arch Allergy Immunol 2002;129:38-48

35. Motoyama K, Ishizaki S, Nagashima Y, Shiomi K. Cephalopod tropomyosins: identification as major allergens and molecular cloning. Food and Chemical Toxicology 2006;44:1997-2002

36. Emoto A, Ishizaki S, Shiomi K. Tropomyosins in gastropods and bivalves: Identification as major allergens and amino acid sequence features. Food Chemistry 2009;114:634-41

37. Arlian L, Morgan M, Vyszenski-Moher D, Sharra D. Cross-reactivity between storage and dust mites and between mites and shrimp. Experimental and Applied Acarology 2009;47:159-72

38. Fernandes J, Reshef A, Patton L, Ayuso R, Reese G, Lehrer $\mathrm{SB}$. Immunoglobulin $\mathrm{E}$ antibody reactivity to the major shrimp allergen, tropomyosin, in unexposed Orthodox Jews. Clinical and Experimental Allergy 2003; 33:956-61

39. Johnston EB, Kamath SD, Lopata AL, Schaeffer PM. TusTer-lock immuno-PCR assays for the sensitive detection of tropomyosin-specific IgE antibodies. Bioanalysis 2014;6:465-76

40. Aalberse RC. Shrimp Serology: We Need Tests with More and Less Cross-reactivity. J Allergy Clin Immunol Pract 2015;3:530-1

41. Lopata AL, O'Hehir RE, Lehrer SB. Shellfish allergy. Clinical and Experimental Allergy 2010;40:850-8

42. Lopata AL, Kamath S. Shellfish Allergy Diagnosis - Gaps and Needs. Current Allergy \& Clinical Immunology 2012;25:60-6

43. Marinho S, Morais-Almeida M, Gaspar A, Santa-Marta C, Pires G, Postigo I, et al. Barnacle allergy: allergen characterization and cross-reactivity with mites. Journal of Investigational Allergology and Clinical Immunology 2006; 16:117-22

44. Giuffrida MG, Villalta D, Mistrello G, Amato S, Asero R. Shrimp allergy beyond Tropomyosin in Italy: clinical relevance of Arginine Kinase, Sarcoplasmic calcium binding protein and Hemocyanin. European Annals of Allergy and Clinical Immunology 2014;46:172-7

45. Khurana T, Collison M, Chew FT, Slater JE. Bla g 3: a novel allergen of German cockroach identified using cockroach-specific avian single-chain variable fragment antibody. Annals of Allergy, Asthma \& Immunology 2014;112:140-5.e1

46. Ayuso R, Sanchez-Garcia S, Lin J, Fu ZY, Ibanez MD, Carrillo $T$, et al. Greater epitope recognition of shrimp allergens by children than by adults suggests that shrimp sensitization decreases with age. J Allergy Clin Immunol 2010;125:1286-93 